\title{
A simple rotation flap for closure of simple and complex pilonidal sinus
}

\author{
Ahmed Alaa, FRCS(Ed) \\ Department of General Surgery, Ain-Shams University, Cairo, Egypt
}

\begin{abstract}
Surgical treatment of pilonidal sinus disease has a significant morbidity and recurrence rate. Controversy still exists regarding the best surgical technique for the treatment of the disease. An elliptical rotation flap has been previously used for pilonidal sinus treatment with no recurrence rate.

In a two-year period, we used this technique to treat 19 patients (17 men and 2 women) with chronic pilonidal sinus with a mean follow-up of 9 months. All patients were discharged on the second postoperative day. Primary healing was achieved in $18(94.7 \%)$ of the patients in 2 weeks with no long-term recurrences. We conclude that this method, in addition to its use in primary sinuses, is particularly useful for recurrent and complex ones with extended tracts where radical excision leaves a large defect.
\end{abstract}

\section{Introduction:}

Pilonidal sinus disease is a common disorder of the sacrococcygeal region. It presents in a variety of ways including asymptomatic, acute pilonidal abscess, chronic pilonidal sinus or complex/recurrent pilonidal sinus disease. ${ }^{1}$ The cause remains controversial. Both congenital and acquired theories have been postulated. ${ }^{2-4}$

Surgical treatment of pilonidal sinus disease is challenging due to high rates of wound infection, impaired wound healing and recurrence of disease after some time. ${ }^{5}$

Various surgical techniques have been used but no method provides the ideal treatment. Sometimes the operation is worse than the disease itself. Excision with a simple lay-open or performing marsupialization both result in a midline wound that takes several weeks to heal and there is a significant recurrence rate because of the open portal for hair insertion. ${ }^{6}$ Primary closure, although associated with a higher rate of recurrence, has been shown to be preferable to excision with an open wound.7-9 It has been suggested that early recurrences may be due to the presence of a wound in the midline acting as a portal for hair entry, and later recurrence may occur because of a deep gluteal furrow, in which loose hair may collect. ${ }^{10-11}$ Following this assumption, the
Karydakis procedure, Bascom's cleft closure and several other procedures that use transposition flaps have been described. 10-12 The latter include the Z-plasty, V-Y fasciocutaneous advancement flap, gluteus maximus musculocutaneous flap, the rhomboid flap of Limberg, N-shaped closure technique and elliptical rotation flap. ${ }^{13-24}$ The common feature of these methods is that they reduce the depth of the cleft and place the suture line away from the intergluteal sulcus and hence have low recurrence rates. $1,2,7$

In this article, we present our results with the elliptical cutaneous rotation flap technique ${ }^{24}$ for both primary and recurrent pilonidal sinuses.

\section{Patients and methods:}

Nineteen patients recruited from the anorectal out patient clinic in Aldemerdash University Hospital were treated with an elliptical cutaneous rotation flap during the period from January 2005 to January 2007.

The procedure was performed under general anesthesia or spinal anesthesia with antibiotic prophylaxis of $1.2 \mathrm{~g}$ amoxycillin-clavulanic acid given intravenously on induction of anesthesia and for 24 hours postoperatively. Patients were placed in the prone position and the operative area was shaved and prepped. The area to be excised, as well as the flap, was 
marked out on the skin Figure(1), before taping the buttocks apart. This was quite important to assure that the edges of the flap will not "sink" in the gluteal cleft as happened in the first patient in this work when marking was done after tension was applied to open the gluteal cleft.

The surgical procedure ${ }^{24}$ was a vertical elliptical excision of all the diseased tissue down to the post sacral fascia Figure(2).

A horizontal cutaneous skin flap of similar size and shape was raised horizontally over the gluteus muscle fascia with $1 \mathrm{~cm}$ pivot point in its lower corner. Its length/width ratio should be $2: 1$. The flap was then rotated about its pivot point to the postsacral defect and sutured subcutaneously with $3 / 0$ polyglactin beginning from its lower edge with the knot tied externally on the skin in the last 14 patients Figure(3). The stitch should include the postsacral fascia so as not to leave a dead space.

The skin was sutured with a subcuticular stitch with supportive interrupted stitches as needed. The flap donor area was closed primarily Figure(4). We used no drains.

All patients were discharged on the second postoperative day with oral pain medication. They were instructed to have bed rest, keeping off their back for two weeks, and observing usual sanitary precautions. The angle stitch and other supportive sutures were removed on the eighth postoperative day. No depilatory creams or hair shaving were advised.

\section{Results:}

There were 17 men and 2 women with a mean age of 23 years (range 17-47). All patients had chronic pilonidal sinus. Five patients had a history of previous infections, which were treated with incision and drainage. Four patients had recurrent pilonidal sinuses previously treated with excision and primary closure $(\mathrm{n}=2)$ or open excision of the surgical wound $(n=2)$.

The procedure was performed under general anesthesia $(n=14)$ and spinal anesthesia $(n=5)$.

The mean operative time was 75 minutes (range 50-80).

Mean follow-up was 9 months (range 612).

Postoperatively Table(1), superficial wound infection occurred in two wounds (10.5\%) and was treated conservatively.

Partial dehiscence of the flap occurred in one patient $(5 \%)$ due to maceration of the edge as it was buried in the gluteal cleft. This was the first patient in the series in whom the marking of the flap was erroneously done while the area was "under tension". Excision and primary suturing of the edge was done due to resistance to healing after 6 weeks of active follow up and dressing.

Stitch sinus at the caudal angle of the flap occurred in two wounds (10.5\%) resulting from the buried Knot of the stitch. After removal of the offending foreign body complete healing was possible. No recurrences were encountered in this trial.

Table (1): Postoperative outcome.

\begin{tabular}{|l|c|}
\hline Mean time to complete healing(d) (range) & $10(8-11)$ \\
\hline Stitch sinus & $\mathrm{n}=2(10.5 \%)$ \\
\hline Partial Wound break down & $\mathrm{n}=1(5 \%)$ \\
\hline Superficial Wound infection & $\mathrm{n}=2(10.5 \%)$ \\
\hline Recurrence & $\mathrm{n}=0$ \\
\hline
\end{tabular}




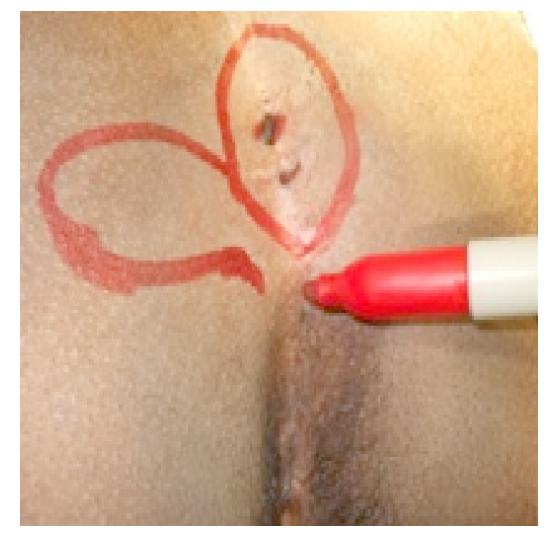

Figure (1): The sinus bearing and a flap of similar size are marked.The pencill points to the $1 \mathrm{~cm}$ pivot of rotation.

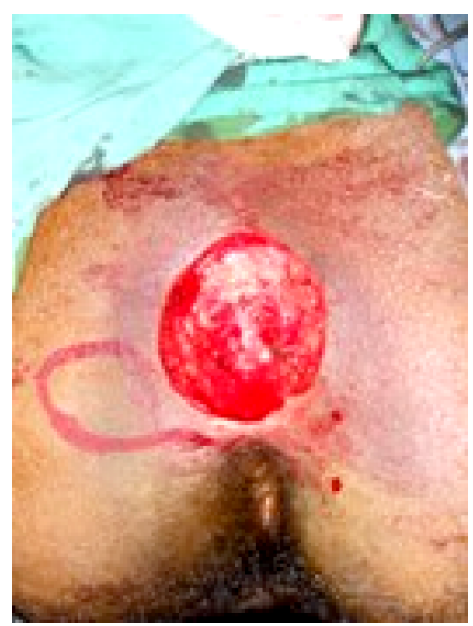

Figure(2): Vertical elliptical excision of all the diseased tissue down to the post sacral fascia leaving a wide defect.

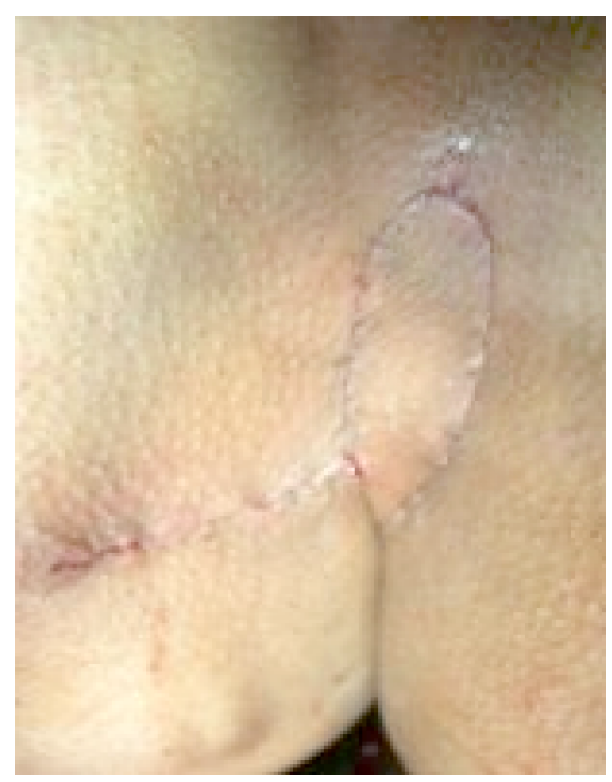

Figure (4): The donor site is closed and the flap covers the defect.

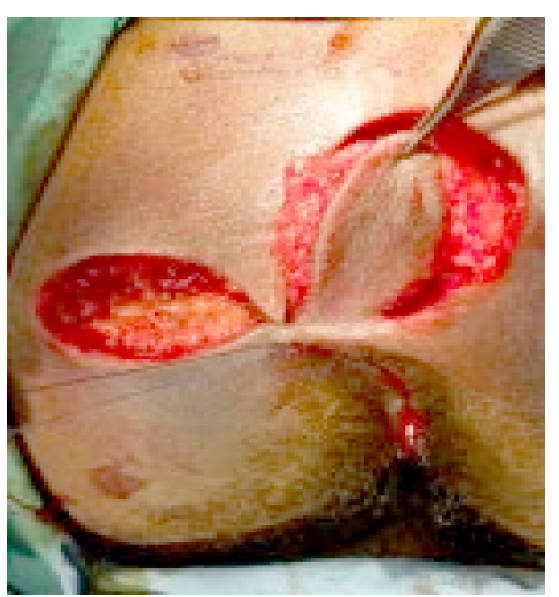

Figure(3): The flap is elevated from gluteus fascia and rotated with the first stitch taken at its lower angle and tied externally over the skin.

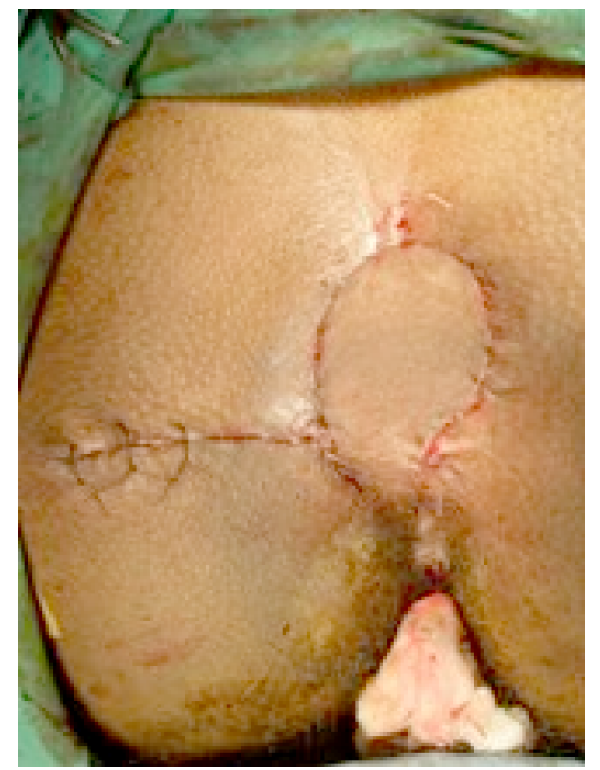




\section{Discussion:}

Pilonidal sinus is a common disorder that affects mainly young males.

The most important predisposing factor for the development of pilonidal sinus is believed to be the existence of a deep natal cleft. A deep natal cleft is a favorable environment for sweating, maceration, bacterial contamination, and penetration of hairs. With frictional movements of the buttocks, hairs tend to penetrate the skin and cause a foreign body reaction and infection that result in a pilonidal abscess or sinus. $5,12,19,20$ Persistence of a deep natal cleft after treatment appears to be one reason for recurrence. ${ }^{21,22}$

The treatment of pilonidal sinus is controversial. The number and variety of published techniques are testament to the complexity of treating pilonidal sinus and the fact that no single procedure is superior in all respect.

Regardless the controversy about the best surgical technique for the treatment of chronic or recurrent pilonidal sinus, an ideal operation should be simple, should not need prolonged hospital stay, should have a low recurrence rate and should be associated with minimal pain and wound care to decrease time off work. ${ }^{12}$

Excision of the diseased tissue down to the post sacral fascia is generally accepted as the "corner stone" step, ${ }^{5-8}$ but the management of the remaining defect is a matter of debate. Thus open excision technique needs long hospitalization and wound dressing daily. Wound breakdown is another disadvantage caused by premature closing of the skin edges before complete wound healing. ${ }^{1-3}$

Primary closure of the wound on the other hand is a simple technique but it has a high recurrence rate due to continuing natal cleft. Another important issue is wound tension. ${ }^{1-3}$

Tension-free closure improves patient comfort and shortens hospital stay.

In this regard, flap procedures, though they have been viewed as "sledgehammer to crack a nut", 25 have all these advantages. The flap technique we used in this work was an elliptical rotational flap described by Nessar et al. ${ }^{24}$

The flap consists of skin and fat and is constructed by extending the incision to the gluteal muscle fascia then is transposed and sutured to the corresponding pilonidal defect. The advantage of this reconstruction is that it flattens the natal cleft with a large, wellvascularized pedicle that can be sutured without tension, any midline dead space is eliminated and a midline scar is avoided. ${ }^{3}$

To address flap survival of the presented technique, the subdermal plexus is considered the source of blood supply to the skin. This network of arterial and venous channels is oriented parallel and adjacent to the skin surface. A random pattern flap based on this subdermal plexus allows elevation of an elliptical-shaped flap of skin and subcutaneous tissue with a length to width ratio in the range of 2 to 1.5:1. Although limited in reach, this random pattern flap can be elevated and rotated to provide viable skin and subcutaneous tissue to close an adjacent wound. ${ }^{26}$

Awad et al. ${ }^{27}$ cutely modified the technique by creating a vertical eccentric elliptical flap instead of being horizontal, as described here, thus avoiding a line of tension along the radius of the arc that may be associated with flap rotation inviting the risk of decreased blood supply to the flap.

Our results with the technique are comparable with other series that have shown recurrence rates of $0 \% .24,27$

In the present series, there were no major wound complications. We learnt from our own observations the importance of marking both the area to be excised and the flap while the patient is prone before distorting the "the normal topography" by the lateral stretching forces applied in such operation. In the latter situation when the tension is released at the end of the procedure one will face the mishap of a deeply buried flap in the gluteal cleft exposing it to a hostile environment. This led to maceration and friction at the edges of the flap that eventuated to partial break down and revision of the wound after a lengthy trial of dressing in one of our patients.

More and again we encountered two wounds with stitch sinus induced by the buried knot of the angle stitch that was perceived by the patients as early recurrence. As this stitch was the "cross-link" between the flap and its site of donation there was a real fear of disrupting 
this bond as we obligatory "dug for" this offending stitch under local anesthesia to manage the induced sinus. Fortunately, both wounds healed uneventfully.

However, and as a preemptive action we then routinely tied the knot externally and was removed on the eighth postoperative day.

The importance of the post-operative wound care after a flap procedure should also be stressed. Exercise or sitting down on the wound should be avoided for few days (two weeks in this series) and the patient has to return slowly to normal activities. ${ }^{20-24}$ Hair removal either by shaving the edges of the wound or by the use of depilatory creams was not mandatory in this trial.

The aim of all surgery should be to minimize both the financial cost to the community and the cost to the patient in terms of time off work, number of dressings and post-operative visits, complications and recurrences. We believe that the elliptical rotation flap for closure of the wound after pilonidal sinus excision meets to large extent these criteria. However, it is important to have a frank discussion with patients when offering them the various surgical options, as the procedure is not without complications and can result in prolonged morbidity in a few cases.

\section{Conclusion:}

Elliptical rotation flap is recommended for patients selected for defect closure specially when the defect is large or the disease is recurrent. It offers improved patient comfort, with an excellent cosmetic appearance and low morbidity.

\section{References:}

1- Werkgartner G: Knowledg-based therapy of the pilonidal sinus. Eur Surg 2004; 36(3): 170-1.

2- Hull TL, Wu J: Pilonidal disease. Surg Clin N Am 2002; 82: 1169-85.

3- Karydakis GE: The etiology of pilonidal sinus. Hellenic Armed Forces Med Rev 1975; 7: 411-6.

4- Williams NS: The anus and anal canal. In: Bailey \& Love's short practice of surgery. Russell RCG, Williams NS, Bulstrode CJK (Editors); London: Arnold (Publisher); 24th edn. 2004; p.1242-71.
5- Katsoulis IE, Hibberts F, Carapeti EA: Outcome of treatment of primary and recurrent pilonidal sinuses with the Limberg flap. Surgeon 2006; 4(1): 7-10.

6- Allen-Mersh TG: Pilonidal sinus: Finding the right track for treatment. $\mathrm{Br} J$ Surg 1990; 77: 123-32.

7- Mentes O, Bagci M, Bilgin T, Coskun I, Ozgul O, Ozdemir M: Management of pilonidal sinus disease with oblique excision and primary closure: Results of 493 patients. Dis Colon Rectum 2006; 49(1): 104-8.

8- Notaras MJ: A review of three popular methods of treatment of postanal (pilonidal) sinus disease. Br J Surg 1970; 57: 886-90.

9- Solla JA, Rothenberger DA: Chronic pilonidal disease: an assessment of 150 cases. Dis Colon Rectum 1990; 33: 75861.

10-Dalenback J, Magnussom O, Wedel N, Rimback G: Prospective follow-up after ambulatory plain midline excision of pilonidal sinus and primary suture under local anaesthesia-efficient, sufficient, and persistent. Colorectal Dis 2004; 6(6): 48893.

11-Kitchen PRB: Pilonidal sinus: Experience with the Karydakis flap. Br J Surg 1996; 83: 1452-55.

12-Bascom JU: Repeat pilonidal operations. Am J Surg 1987; 154: 118-22.

13-Bose B, Candy T: Radical cure of pilonidal sinus by Z-plasty. Am J Surg 1970; 120: 783-86.

14-Khatri VP, Episona MH, Amin AK: Management of recurrent pilonidal sinus by simple V-Y fasciocutaneous flap. Dis Colon Rectum 1994; 37: 1232-35.

15-Rosen W, Davidson JSD: Gluteus maximus musculocutaneous flap for the treatment of recalcitrant pilonidal disease. Ann Plast Surg 1996; 37(3): 293-97.

16-Azab AS, Kamal MS, Saad RA, Abou Al Atta AK, Ali NA: Radical cure of pilonidal sinus by a transposition rhomboid flap. $\mathrm{Br}$ J Surg 1984; 71: 154-55.

17-Gwynn BR: Use of the rhomboid flap in pilonidal sinus. Ann R Coll Surg Eng 1986; 68: 40-41.

18-Williams RS: A simple technique for successful primary closure after excision 
of pilonidal sinus disease. Ann R Coll Surg Eng 1990; 72: 313-14.

19-Bozkurt MK, Tezel E: Management of pilonidal sinus with the Limberg flap. Dis Colon Rectum 1998; 41: 775-77.

20-Erdem E, Sungurtekin U, Nessar M: Are post-operative drains necessary with the Limberg flap for treatment of pilonidal sinus? Dis Colon Rectum 1998; 41: 142731.

21-Cubukcu A, Gonullu NN, Paksoy M, Alponat A, Kuru M, Ozbay O: The role of obesity on the recurrence of pilonidal sinus disease in patients who were treated by excision and Limberg flap transposition. Int J Colorectal Dis 2000; 15: 173-75.

22-Kapan M, Kapan S, Pekmezci S, Durgun $\mathrm{V}$ : Sacrococcygeal pilonidal sinus disease with Limberg flap repair. Tech Coloproctol 2002; 6(1) 27-32.

23-Awad MM, Saad KM: Does closure of chronic pilonidal sinus still remain a matter of debate after bilateral rotation flap? (Nshaped closure technique). Indian J Plast Surg 2006; 39: 157-162.
24-Nessar GT, Kayaalp C, Seven C: Elliptical rotation flap for pilonidal sinus. Am J Surg 2004; 187: 300-3.

25-Khanzada T, Abdul Samad: Recurrence after excision and primary closure of pilonidal sinus. Pak J Med Sci 2007; 23 (3): 375-379.

26-Mathes SJ, Nahai F: Reconstructive surgery: Principles, anatomy, and technique. New York: Churchill-Livingstone (Publishers); 1997.

27-Awad MM, Saad KM, Tolba AM, Gharib $\mathrm{OH}$ : A simple novel technique for closure of simple and complex pilonidal sinus with either simple (tongue-shaped) or bilobed rotation flap. Indian J Plast Surg 2007; 40: 47-50. 